\title{
Mastoid Osteoma
}

\author{
Rabi Hembrom, ${ }^{1}$ Rupam Sinha, ${ }^{1}$ Amit Chakrabarti, ${ }^{1}$ Indranil Sen ${ }^{1}$
}

\section{Introduction:}

\section{ABSTRACT}

Osteoma of the mastoid region is an uncommon benign tumor of bone. Osteomas may occur in the external auditory canals but are reported to be very rare in the mastoid region, with about 150 cases reported in literature.

Case Report:

A 20-year-old man presented with painless lump behind the right ear since last 2 years. On examination a $3 \times 3 \mathrm{~cm}$ tumour was present in the right post-auricular region. HRCT scan showing hyper-attenuating area close to the right mastoid cortex, measuring approximately $3 \times 3 \mathrm{~cm}$, spherical, with cleavage areas between the tumour and the mastoid external cortex. Surgical excision was performed on cosmetic grounds. Postoperative period was uneventful.

Discussion:

Osteoma over the mastoid region is rare and mainly asymptomatic with excellent prognosis after complete removal of the lesion. Keywords:

Osteoma; Temporal bone; Mastoid

$\mathrm{O}$ steomas are osteoblastic mesenchymal tumours commonly located in frontal and ethmoid sinuses. ${ }^{1,2,3,4}$ In the temporal region, osteomas are essentially reported in the external auditory canal, more rarely in the middle ear, styloid process, temporomandibular joint, apex of the petrous temporal bone, internal auditory canal and exceptionally in the mastoid. ${ }^{2,5}$ Mastoid osteoma is rare with about 150 cases having been reported in the literature till $2010{ }^{2,6}$ A literature survey using the above keywords in Google Scholar and PubMed revealed around 20 new publications after 2010, however the exact number of cases reported till date is unknown.

Stuart defined the term mastoid osteoma as a bony tumour of the mastoid; it is benign, circumscribed with slow growth. The size may vary. ${ }^{3}$ It has higher incidence in females, predominantly in the $2^{\text {nd }}$ and $3^{\text {rd }}$ decades of life and is rare in puberty. ${ }^{3}$

Its aetiology is still undefined, but there are many different theories. ${ }^{3,7,8}$ The most accepted hypothesis states that the tumour grows from pre-bone connective tissue.

1 - Midnapore Medical College, Midnapore, West Bengal

\section{Corresponding author:}

Dr Rupam Sinha

email: rupamsinhaad2@gmail.com
The other aetiological hypotheses suggest congenital, traumatic, infectious, hormonal or hereditary causes.

It presents clinically as a slow growing tumour, remaining stable for years. It may produce external deformity. Normally asymptomatic, but may produce pain by invasion of neighbouring structures. Complications include recurrence, facial nerve affection, sigmoid sinus damage and sensori-neural hearing loss. ${ }^{3}$ The entity is diagnosed clinically supported by distinct radiological findings. ${ }^{3}$

Types of mastoid osteomas are: Compact (the most frequent), Cartilaginous, Spongy (rare) and Mixed. 3,6,8,9

The differential diagnoses include: eosinophilic granuloma, monostotic fibrous dysplasia, giant cell tumour, solitary multiple myeloma; osteosarcoma and osteoidosteoma. ${ }^{3}$

The surgical treatment is indicated in symptomatic lesions and for cosmetic reason.

\section{Case Report}

A 20 year old male patient presented with the complaint of a painless, gradually progressive swelling in the right post auricular region. (Fig. 1) The swelling was insidious in onset, which he first noticed 2 years back 


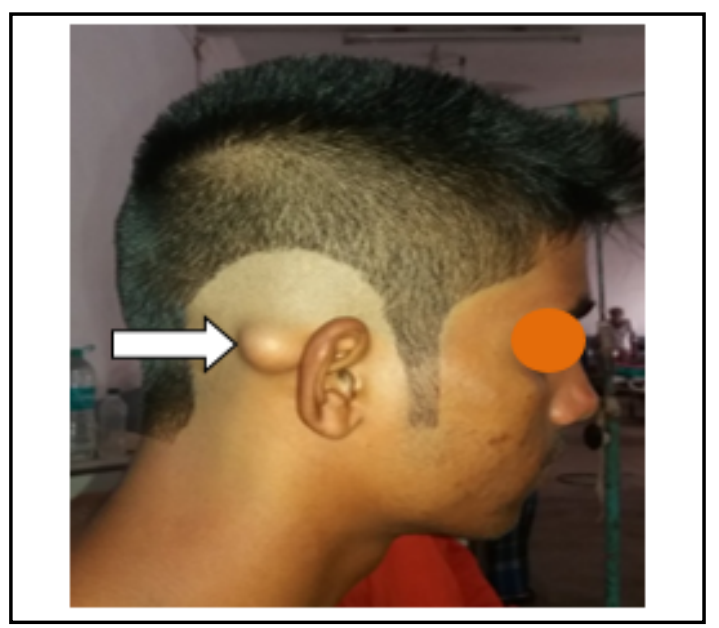

Fig.1: Figure showing right retro-auricular mass

after subtle accidental trauma to the region. There was no history suggestive of any infectious pathology. The family history was unremarkable. Physical examination showed a tumour of approximately $3 \times 3 \mathrm{~cm}$ in the right post auricular region, of bony consistency, smooth surface, rounded, not mobile. Otoscopy was normal. Tests for the facial and other cranial nerves showed no abnormality. Rest of the ENT examination was within normal limits. No other significant abnormality was found in systemic examination. Haematological investigations were within normal limits.

Audiometry showed mild sensorineural hearing loss in the right ear. HRCT temporal bone revealed hyperdense area close to right mastoid cortex, measuring approximately $3 \times 3 \mathrm{~cm}$, spherical, with cleavage areas between the tumour and the mastoid cortex (Fig. 2). There was no evidence of bony destruction or infiltration into the mastoid air cells. Bilateral middle and external ears were normal.

On the basis of above findings, a provisional diagnosis of mastoid osteoma was made and surgical intervention planned for cosmetic indications.

A modified post auricular incision was made over the swelling and subcutaneous flap was elevated. Intraoperatively, the osteoma measured $3 \times 3 \mathrm{~cm}$ and was located $\sim 1 \mathrm{~cm}$ superior to the tip of the mastoid process. (Fig. 3) It had a wide based peduncle with a small slit separating the lesion from the mastoid cortex. Osteoma was removed from base using gouge and hammer and rest of the osteoma was drilled flush to outer table of the skull. The wound was closed in layers over a corrugated rubber drain and stitches were removed seven days after surgery. On regular follow up (two months), no recurrence of lesion was noted. Patient had no cosmetic

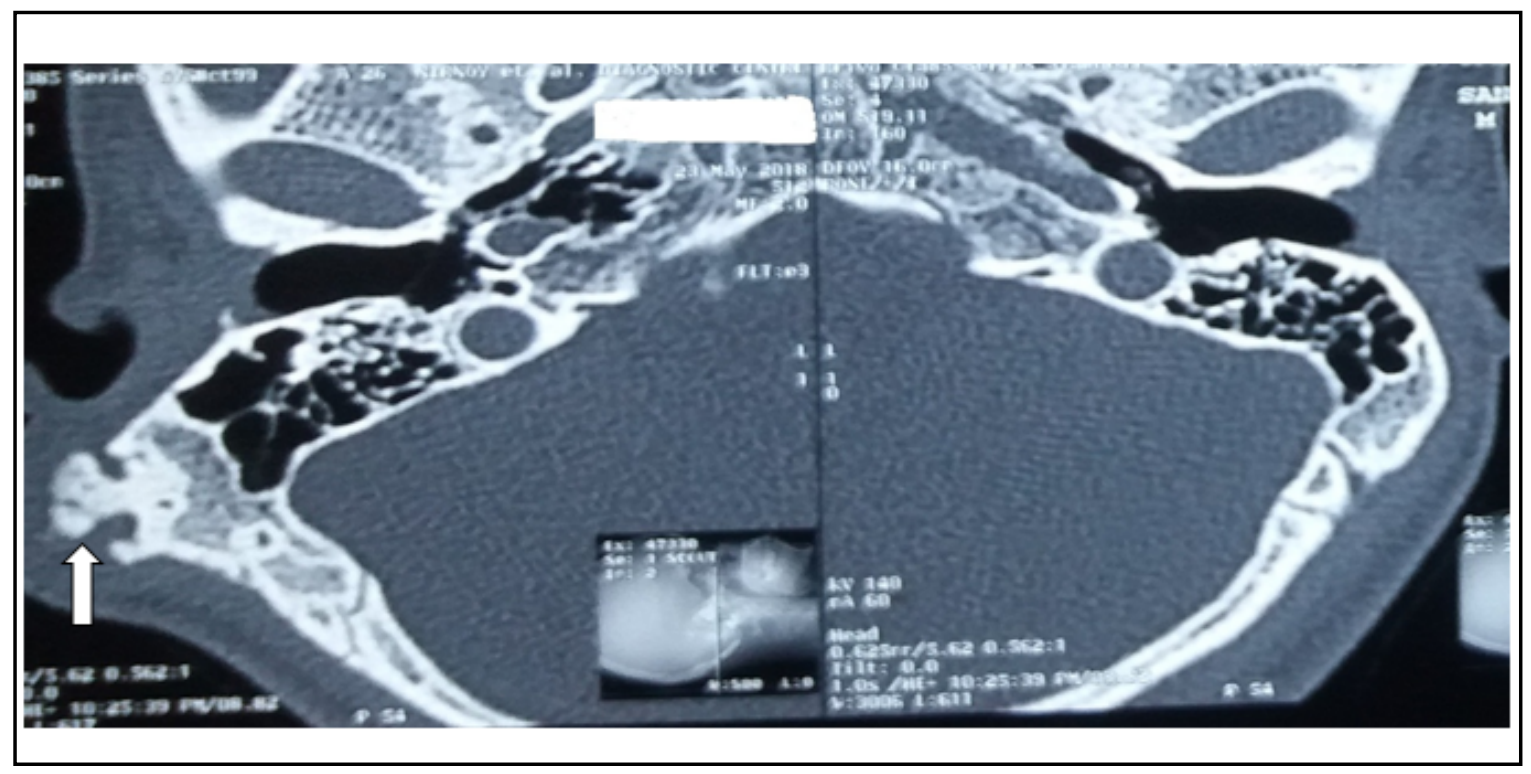

Fig.2: HRCT of temporal bone showing mastoid osteoma 
deformity and no other complaints. Histopathological studies revealed a circumscribed bony lesion comprised of dense, mature, predominantly lamellar bone. Lesion was reported as mastoid osteoma.

\section{Discussion}

The clinical case reported here was diagnosed as mastoid osteoma owing to its clinical, radiological and histopathological characteristics.

The first published report of mastoid osteoma was by Adam Politzer in 1887. Since then, isolated cases of this benign tumour have been published. ${ }^{3}$

While its aetiology remains indefinite, its occurrence may be divided into syndromic and non-syndromic. Gardener's syndrome comprises of multiple intestinal polyps, mesentery and skin fibromas, epidermoid inclusion cysts and osteomas. Osteomas of nonsyndromic origin have several contributing factors to its pathogenesis including trauma, inflammation, metaplasia, surgery etc. ${ }^{1}$

Temporal bone osteomas are usually painless however it can be painful when the osteoma breaches the inner table of the temporal bone; it most commonly presents with cosmetic deformity. Conductive hearing loss can develop due to pushing forward of the posterior wall by the osteoma and occlusion of the external ear canal may cause recurrent ear infection. ${ }^{1}$ Differential diagnoses include osteosarcoma, osteoblastic metastasis, isolated eosinophilic granuloma, Paget's disease, giant cell tumour, osteoid osteoma, calcified meningioma and monostotic fibrous dysplasia. ${ }^{1,5,10}$

On HRCT scan of temporal bone, osteoma can be seen as a rounded bony lesion on the mastoid outer cortex, with distinctive margins with sessile or pedunculated base. Mastoid air cells remain aerated in superficial lesions. Rarely, osteomas may extend into the petrous temporal bone, ossicles and facial nerve with imaging being indispensable to define relations to these structures. ${ }^{1}$

Asymptomatic patients can be followed up with observation. Symptoms such as conductive hearing loss, recurrent ear infection or intolerable disfigurement warrants surgical resection. Mastoid and squamous

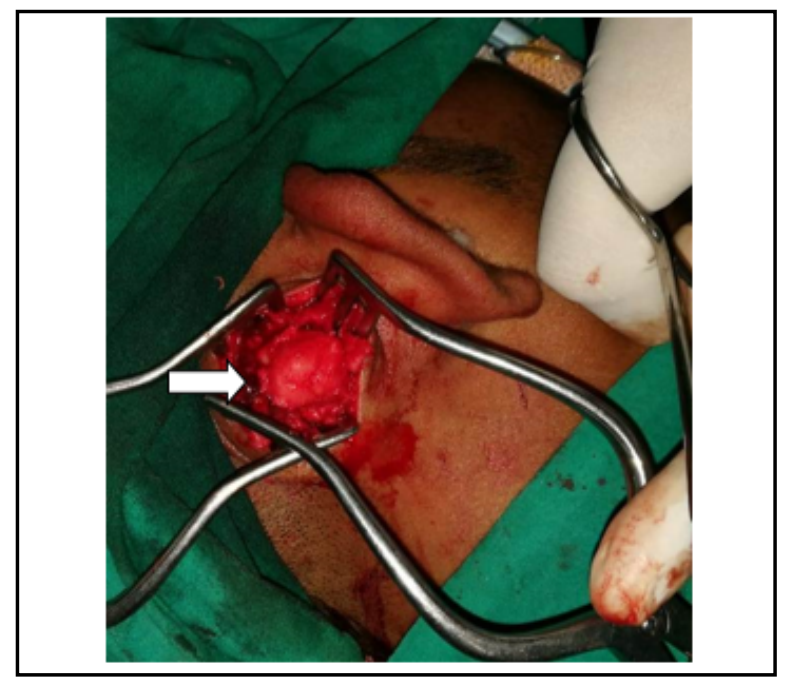

Fig.3: Figure showing intra-operative view of the lesion

superficial lesions are excised and drilled until normal underlying bone is exposed. During excision, periosteal covering and safe margin of the mastoid cortex are removed. Lesions adjacent to facial nerve canal or bony labyrinth is treated with subtotal excision. Complete excision of mass results in excellent outcome with reduced recurrence. Malignant transformation has not been reported. ${ }^{1,4,5,8}$

Complications from surgery are rare. However extensive tumour removal may result in sensorineural hearing loss due to drilling. Patient is also at risk of ophthalmologic complications such as reduced vision and papilloedema due to sigmoid sinus damage when removing a tumour which has extended towards the posterior cranial fossa. Aggressive postoperative medical therapy including steroids and intravenous antibiotics is needed in such cases. ${ }^{1}$

Prognosis is good after complete removal. Two cases with recurrence after treatment has been reported in literature till date. ${ }^{9}$

Mastoid osteomas of temporal bone are rare benign slow growing tumours. They are usually asymptomatic unless it gradually increases in size to cause cosmetic disfigurement. HRCT temporal bone is the imaging modality of choice. Complete surgical excision is treatment of choice. Complete removal of osteoma invariably achieves good cosmetic results. 


\section{References}

1. Al-Yahya SNSH, Hamizan AKW, Zainuddin N, Arshad AI, Ismail F. Mastoid osteoma: Report of a rare case. Egyptian Journal of Ear, Nose, Throat and Allied Sciences 2015; 6:18991

2. Fakiri ME, Bakkouri WE, Halimi C, Mansour AA, Ayache D. Mastoid osteoma: Report of two cases. European Annals of Otorhinolaryngology, Head and Neck Diseases 2011; 128:2668

3. Takenaka PMS, Perez FRP, Patrocínio SJ, Ribeiro JT. Mastoid osteoma: report of a case and literature review. Rev. Bras. Otorrinolaringol. 2004; 70(6):846-9

4. Barati B, Asadi M. Mastoid Osteoma: Report of an Unusual Case. Biomed Pharmacol J. 2016; 9(3):1157-9 doi: 10.13005/ bpj/1063
5. Singh RK, Goyal A, Kumar A, Kataria G, Kesarwani A. Mastoid Osteoma of Temporal Bone - A Rare Case Report. Journal of Clinical and Diagnostic Research: JCDR. 2017; 11(6):MD01MD02

6. Parashari UC, Khanduri S, Singh N, Bhadury S. Mastoid osteoma. Indian J Otol. 2014; 20:132-3

7. Saroch MK. Osteoma Presenting as Solitary Mastoid Swelling. Otolaryngology Online Journal 2016; 6(2):103

8. Das A, Kashyap R. Osteoma of the Mastoid Bone-A Case Report. Medical Journal, Armed Forces India. 2005; 61(1):86-7

9. Alshamsi A, Schmidt E, Marx M. A Case of Mastoid Osteoma. J Otol Rhinol. 2016; 5:4

10. Abdel Tawab HM, Kumar V R, Tabook SM. Osteoma presenting as a painless solitary mastoid swelling. Case Rep Otolaryngol. 2015; 2015:590783 doi: 10.1155/2015/590783. 